\title{
SOCIAL MEDIA RESPONSIBILITY: FACTORS INFLUENCING ACADEMIC PERFORMANCE FOR COLLABORATIVE LEARNING AMONG THE COLLEGE LEARNING STUDENTS
}

\author{
Caoili-Tayuan RR* and Ching MRD \\ De La Salle University-Manila, Philippines
}

\begin{abstract}
Social media has modified the manner we tend to live in some ways. It cannot be regarded as a means of spending time because it has introduced the biggest shift since the times of the Industrial Revolution. Indeed, social media has transformed people's lifestyles and has offered a new pattern of social interaction. This study aims to explore the use of Facebook as a collaborative platform among the college learning students of the UST-IICS. Researching the factors that influence the academic performance of the undergraduates using social media as a venue for collaborative learning came up to a different study. Some may seem very helpful but there are situations that produce a negative outcome. This paper reassesses some descriptions and confers the social software concept. Since this research focused more on the usage of social media, the Honeycomb model for social media was adopted and applied it to the number one social media all over the world, Facebook.
\end{abstract}

This research study is a qualitative case study that can benefit us to recognize the motivations and manners of people, create original insights and ideas, and formulate better research problems and research questions. Based on the study made, many students have positive insights towards the use of social media as a platform for collaborative learning, but there are some who are pessimistic about it. This study has revealed that there is a significant difference between male and female students' responses concerning the right attitude to use social media sites effectively.

Keywords: academic performance, collaborative learning, Facebook, honeycomb model, social media

\section{Introduction}

Millions of people all over the world have been enjoying the advantages of using advanced technologies today. The latest developments in wireless technologies have presented new channels and directions of communication. Societies are now engaged in political, economic, cultural, and educational discourses due to the immeasurable expansion of the World Wide Web. Indeed, social media has transformed people's lifestyles and has offered a new pattern of social interaction.

At present, Facebook must turn out to be one of the biggest networks in the world by means of which people can share and exchange views, images, and photos. Social media has modified the manner we tend to live in some ways. It cannot be regarded as a means of spending time because it has introduced the biggest shift since the times of the Industrial Revolution. Indeed, social networks have altered the traditional image of social communication and have provided new incentives and tools of 
information exchange (Kutsko, E., 2011). What used to be a platform for socialization has currently become a venue for collaborative activities. Social media comprises a variety of online word-ofmouth forums which includes discussion boards, chat rooms, blogs, moblogs (these are sites having digital audio, images, movies, and photographs), and social networking websites (Mangold \& Faulds, 2009). Recent studies presented the evolving role of social media in education and academic networking. It can form groups on social media sites that have aided teachers to connect with students and students to connect with classmates and share important information for the class promptly and without difficulty (Scott, C., 2015).

Facebook being one of the most prevalent and universally used social media networks is chosen in this study as the social network site to ascertain the factors influencing the academic performance among the undergraduate students' adoption processes in an educational framework for collaborative learning. Although Facebook was not formerly designed for educational purposes, it can be used as a virtual environment for discussions and knowledge sharing (Meishar-Tal et al., 2012). Furthermore, (Hasnain et al., 2015), noted that one attainable methodology for using Facebook in teaching and learning is to use its cluster function as a learning management system (LMS) for putting up announcements, allocation of resources, and directing on-line discussions. Bringing social media to the schoolroom is a challenge for educators due to numerous concerns such as access to social media, users' privacy, and possible cyberbullying. Many studies have been made and discoursed the usage of Facebook as the social media platform for educational requirements and students thought confidently about it. With all such realities, it is the goal of the study to identify the factors influencing the academic performance for collaborative learning among undergraduate students using social media platform such as Facebook.

\section{Research Problems}

This study aims to explore the use of Facebook as a collaborative platform among the college learning students of the UST-Institute of Information and Computing Sciences.

Specifically, the study aims to answer the following research questions:

1. What are the students' usage and perception of social media on academic performance for collaborative learning?

2. How do students perceive the use of social media as an effective tool for collaborative learning to improve their academic performance?

\section{Related Literature}

It has been studied that since the growth of social media evolves, the attention of higher education has switched from the power on knowledge skills into underlining long-learning in terms of proficiencies (Junco, 2012).

\section{Social Media}

Social media plays a big role for many years now, it has been used to be a platform for socialization that becomes a setting for collaborative activities. Several researchers have defined it in different 
views, so as (Hasnain et al., 2015) stated that there is no single standard characterization of social media. A standard media is a web-based application which likely to create and simply transmit contents in the form of words, photos, videos, and audios.

\section{Academic Performance}

It is the needy variable of this study and is identified as the performance of a students' academic achievements. Academic performance at the university level is counted to the mark if the student has sustained his General Weighted Average (GWA). However, there are external factors that may disturb a student's academic performance, and one of those is the time spent using social media. One of the objectives that must be investigated is to identify the effect of social media on the academic achievements of the students and uncover whether it has a negative or positive correlation.

\section{Social Media Usage on Academic Performance}

According to (Pasek et al., 2009), Facebook usage has a positive influence on academic performance. Based on their research, students with higher grades manage to use more of their time browsing Facebook.

\section{Social Media Use and Engagement}

This study aimed to explore Facebook as room for interaction and collaboration. According to (Kietzmann et al., 2011), the society defined social media as a tool that can be used to share, cocreate, and a venue for conversation of a user-created content, it is any form of content, such as images, videos, audio and text, which have been posted by users.

\section{Social Media Use and Collaborative Learning}

Collaborative learning is categorized by student exchanges and connections with course content. According to (Chen \& Bryer, 2012; Friesen \& Lowe, 2012), social media prepares an opportunity for learners to expand their learning environment since only a segment of student learning exists within the borders of a classroom.

\section{Facebook as a Learning Management System}

It has been talked about and studied that Facebook has been used by educators as an opportunity for the teaching-learning process and to broaden the platforms for learning and creating it worthwhile to use in designated classes. The study aimed to measure the effectiveness of using the Facebook group as instructional technology, specifically in increasing the achievement of the students with academic activities (Pecson, R., 2016).

\section{Theoretical Framework}

This paper reassesses some descriptions and confers the social software concept. Since this research focused more on the usage of social media, the Honeycomb model for social media was adopted and applied it to the number one social media all over the world, Facebook. Based on the concept from (Morville et al., 2006) for a framework to illustrate the components of user experience honeycomb, 
Smith (2007) suggested a framework to epitomize a list of seven elements that give a functional definition to social software (cf. Figure 1). Smith constructed the social software honeycomb wanting to provide a basis for understanding the working of social software and then, for defining the components that should be considered when planning them.

\section{The Honeycomb Model for Social Media}

There are seven building blocks for social software: identity, presence, relationships, reputation, groups, conversations, and sharing. These building blocks are not commonly limited and need not all be presented in a social media engagement (Smith, 2007). Another study from (Kietzmann et al., 2011), these building blocks are structures that make sense of how distinct levels of social media functionality can be constructed. Each function will make sense of how environmental practitioners will assess social media and appreciate the scope of interactions and appointments to use.

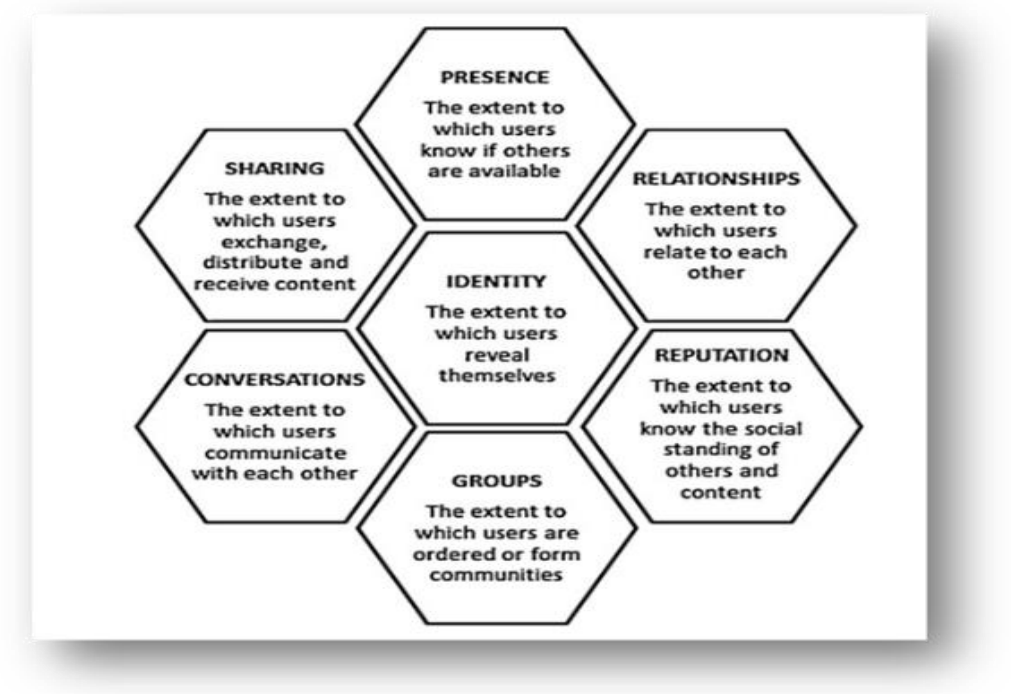

Figure 1. The Honeycomb Model for Social Media

The study explored each block to understand the practical traits of several social media activities and the vital inferences that each block presents to the students as they seek ways to involve their classmates and teachers in academic collaboration. The identity block is the focus placed at the center since it is the most basic functional requirement of any social software system. It is a way of recognizing people in the system and the extent to which individuals or groups make their individuality public in a social media venue (Babac, 2011).

Based on the studies made by Smith in different social media sites, the researcher identified only five out of seven blocks were adopted by Facebook based on the ripostes of the respondents from the interview: identity, presence, sharing, conversations, and groups. The honeycomb model was explored by analyzing Facebook as a platform used by college students for collaborative learning. This analysis recognizes the components considered by the system, expounded the qualities of how these components were applied and present which points are not being involved by the framework. 


\section{Research Method}

This research study is a qualitative case study. Descriptive case studies refer to an instance or interference in the context it appears (Yin, 2017). The case study research has grown in reputation as a valuable method to explore and understand multifaceted issues in real-world situations. The case in this study is the use of social media sites, Facebook, as a tool for learning and as a content management system. In addition, a case study is in-depth research of a bounded system of a certain situation or event (Clark, 1999). This approach growing in the up-to-date years because it is based on real-world experiences.

\section{Population and Study Sample}

The respondents of the study have a total of 15: 12 first year and third-year Information Technology undergraduate students, and 3 faculty members of UST-Institute of Information and Computing Sciences (UST-IICS) during this First Semester of the Academic Year 2019-2020. Of the 12 participating students, there were 6 females and 6 males: while 1 female and 2 males of the participating faculty members. The age of the respondents ranges from 18 to 25 years old (students) and 35-50 years old (faculty).

\section{Research Instruments}

A qualitative approach was used for this study to investigate the behaviors and perceptions of undergraduate IT students' usage of Facebook in an educational setting for collaborative learning. The researcher informed those potential respondents regarding the schedule of when they will be scheduled for a face-to-face or personal interview with a single respondent. They were given an orientation on what the purpose of the said interview, how long will it last, the sample questions that will be asked from them, and the security of their identity.

\section{Data Collection Tools}

Upon completion of the study, the 12 students as respondents were invited to answer the seven (7) open-ended questions to determine the respondents' levels of satisfaction and perceptions and the main target is to make sure that all respondents will be able to accomplish the questionnaire.

1. How do you find the tasks done by everyone such as sharing, of course, notes (e.g., PowerPoint), eBooks, journals, articles and news articles, videos, photos, homework, and more through Facebook?

2. What do you think about synchronous and asynchronous communication (instant messaging/chat and group discussions) on the Facebook wall?

3. How do you find Facebook as a tool for collaborative learning among college students? Are there challenges you have experience in using Facebook?

4. Do you agree that Facebook is not only for socialization but also for collaborative learning among students?

5. Do you communicate with your professors using Facebook (i.e., Facebook Group Chat, link to resources provided by the teacher) with reference to academics?

6. Do you think Facebook is safe and can be used both socially and for educational purposes? 
7. What are your recommendations to develop the effectiveness of the use of Facebook in academic performance for collaborative learning?

\section{Data Analysis}

Content analysis was applied to the data that was gathered from the open-ended questions. Each response for each number has read more than once, has been transcribed, and a frequency of the table was created. Arguments and/or ideas that were transpired has been assessed and reviewed. Significant notions and assertions by the respondents were comprised as quotations to prove the outcomes. Further study and analysis will be implemented if necessary.

\section{Ethical Consideration}

The data that was collected in the study was gathered from the faculty and students who are using the Facebook group as an instructional tool for one of their courses responded with the questions stated above. There is a letter addressed to the respondents attached to the questionnaire to express the justification of the study. In managing the data that will be gathered, the researcher guaranteed the confidentiality of them and the obscurity of the respondents' identity.

\section{Results and Discussion}

Mainly the center of this study was to explore the students' engagement in social media such as Facebook usage and its effects on students' academic performance in a collaborative learning environment. Social media use in collaborative learning enhances the academic performance of students as it enables high interaction with educators, develops communication skills and agrees with the exchange of information among students and educators. The collaborative learning and engagement through social media (such as Facebook) usage aid the students' intention to utilize social media as it prepares them to be confident enough in presenting their work via social media brought about by such collaboration. This makes it easy for both students and educators to acquire pertinent resources, information, and knowledge.

\section{Facebook platform as the venue for academic collaborative learning}

This study presented that Facebook has transformed into a venue for academic collaboration, and not just for socialization as its first purpose. For this study, the students and the educators maximized the use of Facebook in achieving and concluding their course requirements until the end of the academic year. Despite the existence and the student's dynamic usage of the Moodle, Canvas, and Blackboard's official learning tool in the university, it performs as a second nature for most students to use Facebook in their collaborative work. The following priori codes materialize on how students and educators view Facebook as a venue for academic collaboration:

\section{Ethical Consideration}

Facebook page and group chat are considered as a venue for storing, sending, uploading, downloading and sharing of course materials and other resources individually both by students and educators. (Glowatz \& O'Brien, 2013) studied that Facebook arranged the students to partake in the university transactions vis-à-vis information sharing. 
Students and educators shared their thoughts transpired as themes in response to the first open-ended question. One student's statement has chosen and stated the following:

SR1 (Male): "In my opinion, sharing course notes or any school-related material is really convenient for both the professor and the students. Since almost everyone is connected to Facebook, it is a convenient platform for information to disseminate. It allows both parties to sign up for a new platform to do these things such as using "portals" for e-learning".

According to one educator:

ER1 (Male): "As an educator, sharing my course materials via Facebook is just fine especially that my resources are all accessible through Google drive. I'm setting apart the materials that are safe to share with my students (student mode files) versus to those that are not for students viewing".

(McLoughlin \& Lee, 2014) concluded that as per teaching methods that shift in the direction of more personalized, participatory, and inventive learning techniques via social media, such as Facebook, embolden students by providing them a voice and channel for self-expression as well as a computergenerated space within which they can collaborate and play a role to the generation of shared concepts and resources.

Despite having positive thoughts, students and educators mentioned that there are some technical problems that may be encountered while sharing and downloading their course materials: low-speed internet connection (or mostly, out-of-data), large file sizes, and required file format. This means that the sharing functional building block of Facebook as specified in the honeycomb framework occurred and made a big impact regarding the Facebook usage.

\section{Collaborative Learning}

Positive and negative thoughts transpired as themes in response to the third open-ended question on students' opinions concerning the usage of Facebook as a tool for collaborative learning.

The following statements from a student's articulate a positive opinion:

SR1 (Female): "I think Facebook can be used as a tool for collaborative learning among college students. Facebook is a huge platform because of its many users. Almost everyone uses it, so it will be more effective for the students to collaborate with their other groupmates".

One student uttered their views that somehow, they do not agree with using Facebook as a tool for collaborative learning. The following are stated below:

SR1 (Female): "The usage of Facebook as an academic tool has its downside. It is the distraction it can make for students who are focusing on doing something, but since Facebook has a wide variety of entertainment, students would be easily distracted".

Based on the following views of the students, not all Facebook users are confident in using Facebook as a venue for collaborative learning. Most of the students use Facebook during their studies as their past time and in their view, Facebook does not complicate them from doing studies or schoolwork. 
Because Facebook is such an application that can run in the background of internet devices so there is no need for users to get involved with Facebook regularly.

According to one educator:

ER1 (Female): "Using social media sites such as Facebook, Twitter, Instagram, LinkedIn, and more are somehow not an appropriate tool as a venue for collaborative learning, discussion and even with work. We will always get distracted in anything that we do by means of non-stop notifications every time there will be member(s) sending messages, reacting with the messages, or posting. Aside from a fact, that not all students are fond of using Facebook. Believe it or not, there are still students and teachers who does not have their Facebook account".

It was concluded that those students and educators who do not have a Facebook account might have been some security injustice. It is also discovered that most of the non-Facebook users have preferred that they do not use Facebook because they do not want to put their personal data on the internet and those users are not interested at all in using Facebook. This implies that the relationship block of honeycomb does exist but not necessary to be present to look forward to collaborative academic and employment activity.

\section{Social Interaction}

It was 2004 when social media such as Facebook started, initially for students, as a social communication tool. Most activities are purely social, such as confirming friends and communicating (R (Ruth) De Villiers, 2010). It is where students meet their new friends and renew their former acquaintanceships and write on each other's "walls".

Students responded:

SRI (Male): "I guess, I can say that it's much easier to search for the people we're trying to find in Facebook than anywhere else as its algorithm makes it easier to search absolutely everyone".

One educator responded:

ER1 (Female): "Using this social media (Facebook), helps me to locate my friends, relatives, schoolmates here and abroad. Very helpful as well to communicate with my friends and colleagues in private and public groups".

This kind of assessment is favored by (Avram, 2014) and stated that Facebook in academe initiates the beginning for sufficient socializing, which agree to the members of an academic society to get to know each other better. Building a new friendship are those students who were living and working in the same locale. This means that the groups' functional building block of honeycomb occurs as students and educators were able to form their own communities on Facebook either for work or friendship groups.

\section{Concerns, Restrictions, and Issues}

Both students and educators do face concerns, restrictions, and issues in utilizing Facebook in their academic works. The following are their major concerns: 


\section{Connectivity}

Connectivity has another connotation in this condition. It is not one of the main concerns here but to properly communicate and collaborate with the group members, internet connection is needed. Having poor internet connectivity or no connection at all will be a big hindrance to all members of the group especially with their academic work.

\section{Communication}

Communication is the main factor why the Facebook group has been executed and is continuously growing and utilizing by almost 2.45 billion Facebook users (statista.com 2019). Simultaneously, this is one of the challenges as well to everyone, in the academe, a challenge for both the students and educators by using it as a venue for online collaboration. On the side of the educator, monitoring and maintaining regular communication with the students must be given priority.

Despite all this difficulty, the students managed to maintain their active communication via Facebook group chat by getting in touch with one another especially those who are not dependable in using social media. Involve here is the coordination of each member to work well. Educators are concerned with their students' different personalities, profiles, and experiences which is one thing that must be considered having this online collaborative learning.

\section{Commitment}

One of the issues in the group is a commitment to students' behavior varied. There are some students that were not attentive, hardworking, and mostly are tenacious to have the courage of knowing their responsibilities and roles for the team. Not all members are willing to contribute and give their time to work with the academic group activity that sometimes leads them to the unfinished projects and ended with miscommunication.

\section{Recommendations and Future Implications}

The following are the recommendations and its implementation plan for future researchers who might want to enhance and accomplish a similar study:

1. An additional number of respondents (both students and educators) in different colleges and year level to get more data concerning the factors affecting them through the usage of social media sites not just with Facebook but may include other social media sites such as Flickr, YouTube, etc.

2. Have a comparison testing between social media sites versus learning management systems that are also been using and official tool of the university for collaborative learning, this is to weigh the usage of each tool to assess if social media sites such as Facebook can be accepted as an official platform of the university which can be implemented and utilize for the academic activity.

3. Future studies may include additional elements such as "Emotion and Affection" (Sellen et al., 2009)that will measure factors influencing the academic performance of students through collaborative learning and engagement in the whole university which is another point that can be addressed by the honeycomb framework. 
For the students to be more disciplined on the proper usage of social media, organize training and workshop sessions for learning purposes. If given permission to include the use of social media, stipulate a number and acceptable social media sites to be used for learning and teaching.

\section{Conclusion}

The general conclusions in this study illustrated that the college students and educators highly accepting and adopting the consumption of social networking sites as a medium to be the main venue of class collaborative learning in the institute and they are currently and previously utilizing it already. It is discernible that social networking tools have the capacity to be a desirable tool for institute students and educators' communication and interaction. In general, it was marked that the students demand a more collaborative learning environment that consents them to have greater opportunities to handle and organize their online collaborative learning environment.

It has been observed the role of the educators as well in this study. Their presence is to guide and monitor the students with their online collaborative learning environment throughout this first term of the current academic year. Moreover, it is extensive for the whole university to be cognizant of the students' contemporary needs and interests associated with their learning environment for better knowledge achievement and academic performance.

The Honeycomb framework with seven functional blocks was the theory adopted in this study and five of these blocks have been associated with the use of Facebook as a collaborative platform among the college learning students of the UST-IICS: identity, presence, sharing, conversations, and groups. It is a fulfillment knowing that the study attested that Facebook should be recognized as an alternative tool for a collaborative learning environment among the students. Social media has a prospective to be beneficial learning standards and an influential learning medium, but individual users must fathom the right behaviors (the how's and why's) through which social media should be utilized in a positive ethical approach.

Educators must never replace a good teaching scheme, in spite of experiencing a never-ending opportunity by social networking sites. Educators must plan the right method for the learning process, they need to patently enunciate the course objectives, learning goals, and student outcomes. According to (Tay \& Allen, 2011), educators must develop an outline and organize teaching activities that involve students and entail collaborative participation, concentrating on concepts and indemnifying that the students be familiar with the course materials and resources.

\section{Acknowledgements}

The accomplishment of this study could not have been conceivable without the expertise of Asst. Prof. Jordan Deja, one of my mentors in research. I would also like to thank Mr. Jude Lumer and Mr. Vince Pitogo for helping us out with my study. A debt of gratitude is also owed to Dr. Nelson Celis our professor in DIT571D for providing us with the guides for our framework.

Lastly, I would like to thank my DIT batchmates, my IT students, and my co-faculty in UST for their never-ending support at all times. 


\section{References}

Avram, E. M. (2014). FACEBOOK COMMUNICATION. II(3), 129-134.

Babac, R. (2011). Impact of Social Media Use on Brand Equity of Magazine. 15, 58.

Chen, B., \& Bryer, T. (2012). Investigating instructional strategies for using social media in formal and informal learning. International Review of Research in Open and Distance Learning, 13(1), 87104. https://doi.org/10.19173/irrodl.v13i1.1027

Clark, A. (1999). Qualitative Inquiry and Research Design: Choosing Among Five Traditions, by John W. Cresswell. In Western Journal of Nursing Research (Vol. 21, Issue 1, pp. 103-105).

Friesen, N., \& Lowe, S. (2012). The questionable promise of social media for education: Connective learning and the commercial imperative. Journal of Computer Assisted Learning, 28(3), 183-194. https://doi.org/10.1111/j.1365-2729.2011.00426.x

Glowatz, M., \& O'Brien, O. (2013). Facebook in an academic environment: Advancing practice from information-sharing to collaboration and innovation (ICI). $26^{\text {th }}$ Bled EConference - EInnovations: Challenges and Impacts for Individuals, Organizations and Society, Proceedings, Ici, 154-177.

Hasnain, H., Nasreen, A., \& Ijaz, H. (2015). Impact of Social Media Usage on Academic Performance of University Students. Langkawi, August, 26-27.

Junco, R. (2012). Too much face and not enough books: The relationship between multiple indices of Facebook use and academic performance. Computers in Human Behavior, 28(1), 187-198. https://doi.org/10.1016/j.chb.2011.08.026

Kietzmann, J. H., Hermkens, K., McCarthy, I. P., \& Silvestre, B. S. (2011). Social media? Get serious! Understanding the functional building blocks of social media. Business Horizons, 54(3), 241251. https://doi.org/10.1016/j.bushor.2011.01.005

Mangold, W. G., \& Faulds, D. J. (2009). Social media: The new hybrid element of the promotion mix. Business Horizons, 52(4), 357-365. https://doi.org/10.1016/j.bushor.2009.03.002

McLoughlin, C., \& Lee, M. J. W. (2014). Beyond friending: Psychosocial engagement on facebook and its implications for academic success. An Education in Facebook?: Higher Education and the World's Largest Social Network, December 2016, 43-52.

Meishar-Tal, H., Kurtz, G., \& Pieterse, E. (2012). Facebook groups as LMS: A case study. International Review of Research in Open and Distance Learning, 13(4), 33-48. https://doi.org/10.19173/irrodl.v13i4.1294

Morville, P., Challis, T., Findability, A., Nasr, M. S. El, Arab, A., District, D., District, D., Circles, T. T., \& While, I. A. (2006). User Experience Design User Experience Design Page 2 of 4. 27-30.

Pasek, J., More, E., \& Hargittai, E. (2009). Facebook and academic performance: Reconciling a media sensation with data. First Monday, 14(5). https://doi.org/10.5210/fm.v14i5.2498

R (Ruth) De Villiers, M. (2010). Academic Use of a Group on Facebook: Initial Findings and Perceptions. Proceedings of the 2010 InSITE Conference, November, 173-190. https://doi.org/10.28945/1242

Sellen, A., Rogers, Y., Harper, R., \& Rodden, T. (2009). Reflecting human values in the digital age. Communications of the ACM, 52(3), 58-66. https://doi.org/10.1145/1467247.1467265

Tay, E., \& Allen, M. (2011). Designing social media into university learning: Technology of collaboration or collaboration for technology? Educational Media International, 48(3), 151-163. https://doi.org/10.1080/09523987.2011.607319

Yin, R. k. (2017). Case Study Research and Applications: Design and Methods, Sixth Edition. 